\title{
Adjusting Time for Uncertain Project Assessment
}

\author{
Salvador Cruz Rambaud ${ }^{1} \&$ Ana María Sánchez Pérez ${ }^{1}$ \\ ${ }^{1}$ Departamento de Economía y Empresa, Unversity of Almería, Spain \\ Correspondence: Ana María Sánchez Pérez, Departamento de Economía y Empresa, Unversity of Almería, La \\ Cañada de San Urbano, Ctra. Sacramento s/n, (04120) Almería, Spain. Tel: 34-95-0214-165. E-mail: \\ amsanchez@ual.es
}

Received: April 19, 2016

Accepted: May 6, 2016

Online Published: June 25, 2016

doi:10.5539/ijef.v8n7p275

URL: http://dx.doi.org/10.5539/ijef.v8n7p275

\begin{abstract}
This paper presents a novel methodology to include the risk when determining the net present value of an investment. More specifically, the risk of cash flows is priced by the delay in the payment of debts not at the initially agreed maturities, but at later dates. To do this, first we recall the classical methods which introduce a certain risk correcting parameter before determining the net present value of the project. The key idea of this new model is to transfer the risk to the time embedded in the expression of the discount function by using a suitable deformation of this parameter. In this way, the risk is measured by the delay in the initially agreed maturity when obtaining the corresponding cash flow. On the other hand, the way to include the risk in a project is based on an adaptation of the Krugman's curve which describes the relationship between debt maturities and their respective expectations of being obtained. The empirical contribution is based on the use of real data of payment delays corresponding to Spanish companies in 2015. This procedure allows to fit the risk of an investment project from a more realistic perspective and so to determine more accurately its net present value.
\end{abstract}

Keywords: investment project, risk, net present value, deformation of time

\section{Introduction}

In this paper we present a novel methodology to introduce the risk when determining the net present value (NPV) of an investment project. In effect, it is well known that:

$$
N P V=-I_{0}+\sum_{t=1}^{n} C F_{t}(1+i)^{-t}
$$

where $I_{0}$ is the investment at time $0, C F_{t}$ is the expected cash flow corresponding to period $t(t=1,2, \ldots, n), i$ is the interest rate, and $n$ is the number of periods (De Pablo, 1991, 1998 and 2000). The risk inherent to the investment project can be embedded in Equation (1) by considering several methods to modify the parameters defining the NPV (Gil Peláez, 1992) so that the present value can be determined following a criterion of prudence (Jiménez, 2003). More specifically, two different approaches can be implemented, in this paper a brief review of existitng model is done in section 2 and 3 :

1) If the cash flows are random variables, they can be substituted in Equation (1) by their respective mathematical expectations:

$$
N P V=-I_{0}+\sum_{t=1}^{n} E\left(\xi_{t}\right)(1+i)^{-t}
$$

where $\xi_{t}$ denotes the random cash flow associated to period $t(t=1,2, \ldots, n)$, and then they can be multiplied by an adjusting factor based on the standard deviation of each random variable (see Section 2).

2) If the cash flows are not random variables, we can modify the interest rate and the time parameter. Inside this second alternative, there are several possibilities: 
a. To introduce an adjusting factor for the cash flows as previously indicated in the approach 1 (see Section 2).

b. To introduce an adjusting parameter for the interest rate (see Section 3):

i. By summing up a premium to the interest rate.

ii. By introducing a factor affecting the interest rate.

c. To introduce an adjusting factor for the time (see Section 3).

A noteworthy advantage of the last two models is that they treat the risk by considering the project as a whole. Nevertheless, they exhibit the disadvantage of determining the concrete values of the risk parameters suitable for each project. Take into account that the choice of an adjusting factor or risk premium may entail a high degree of subjectivity by the analyst. In other words, an inaccurate choice of parameters may imply that the emerging results do not represent the expected value properly (Gil \& Gil, 1987) and so it should be necessary to proceed carefully.

This paper aims to quantify the Net Present Value corresponding to a risky or uncertain investment where the risk is represented by the possible deviation of the expected values of the cash flows involved in the project. To do this, we can use 'direct' methodologies such as introducing an adjusting factor to cash flows, or 'indirect' procedures such as introducing a risk premium, introducing a divisor to the discount rate or introducing a multiple to cash flow maturities. With respect to the procedures involving the interest rate, it is necessary to take into account the "return/risk binomium". In effect, if the profitability required to a certain investment is given, a risky investment (due to uncertain cash flows) will require an upper return. This is the reason whereby a risk premium is summed up to the profitability or the interest rate is affected by a divisor: the resulting NPV is thus more conservative.

Traditional models do not properly price the risk associated to the cash flows. Indeed, this justifies the implementation of a new, more objective model to quantify the risk inherent to a project. In this paper we aim to include the risk in the project assessment by deforming the time which represents the maturity of each cash flow. In this way, our paper generalizes the last methodology used to include the risk (introduction of an adjusting factor for the time) because it can be considered as a linear deformation of time. For this purpose, we also start from the formula of the $N P V$ (Fernández, 1992) where the future cash flows are discounted by using a given rate of interest (constant or variable), and then their aggregate value is compared with the investment at instant 0 (Brealey \& Myers, 2002; and Brealey et al., 2014). The calculation of the net present value uses a simple and intuitive formulation which takes into account the value of money over time when discounting future cash flows (Loring, 2007).

To avoid the problem of the subjectivity underlying to the risk parameter used to value, in this paper we are going to consider the risk as a function of the perception (Loewenstein et al., 2003) that creditors have about possible delays in the receipt of payments by debtors. As a result, the project risk is transferred to the parameter time of the discount function used for the assessment. So the use of this model provides a risk-adjusted value of the time parameter that allows discounting future cash flows from a more realistic perspective than the traditional ones. To do this, we will base our approach on real data of delays in payments.

The organization of this paper is as follows. In Section 2, the model to introduce the risk in the expression of the $N P V$ is presented by adjusting the cash flows by a suitable coefficient. Section 3 considers the risk based upon the adjustment of the discount rate and time, showing the relationship between the parameters used in each method. Section 4 presents our novel methodology which is the main contribution of this paper. Finally, Section 5 summarizes and concludes.

\section{Using an Adjusting Factor to Cash Flows}

This procedure consists in multiplying each cash flow, $C F_{t}$, by an adjusting factor, $\alpha_{t}(t=1,2, \ldots, n)$. This coefficient must be between 0 and 1, and the higher is the risk the smaller the coefficient (Cruz and Valls, 2008). The modified net present value when including these coefficients, denoted by $N P V^{*}$, is:

$$
N P V^{*}=-I_{0}+\sum_{t=1}^{n} \alpha_{t} C F_{t}(1+i)^{-t}
$$

In the particular case in which the coefficients are constant, $\alpha_{t}=\alpha$, for every $t$, the modified net present value, 
denoted by $N P V^{* *}$, would remain as follows:

$$
N P V^{* *}=I_{0}+\alpha \sum_{t=1}^{n} C F_{t}(1+i)^{-t}
$$

Indeed the difficulty of this methodology consists in specifying the values of $\alpha_{t}$ or the value of the unique coefficient $\alpha$. Nevertheless, if the cash flows involved in the project are random, the coefficients $\alpha_{t}$ can be approximated according to the standard deviation, $\sigma\left(\xi_{t}\right)$, and the mean, $E\left(\xi_{t}\right)$, of each cash flow $\xi_{t}$, since the risk can be defined as the relative deviation of this random amount with respect to its expected value. In this way, a possible procedure solution could be a suitable multiple of the coefficient of variation defined by $C V_{t}:=\sigma\left(\xi_{t}\right) / E\left(\xi_{t}\right)$. Thus,

$$
\alpha_{t}=1-\lambda C V_{t}
$$

where $\lambda$ is a subjective constant parameter whose value is determined by the condition that the adjusting factor must vary between 0 and 1 , that is, $0<\alpha_{t}<1$, for every $t$. Below, we can see the concrete expression of the modified net present value by using the adjusting factors defined in (5):

$$
N P V^{*}=-I_{0}+\sum_{t=1}^{n}\left[1-\lambda\left(\sigma\left(\xi_{t}\right) / E\left(\xi_{t}\right)\right)\right] E\left(\xi_{t}\right)(1+i)^{-t}=\sum_{t=1}^{n} E\left(\xi_{t}\right)(1+i)^{-t}-\lambda \sum_{t=1}^{n} \sigma\left(\xi_{t}\right)(1+i)^{-t} .
$$

Observe that, in this procedure, the subjectivity is translated to the parameter $\lambda$ which makes the choice of the values of $\alpha_{t}$ easier. This is because the coefficient of variation of the random variable $\xi_{t}$ indicates the uncertainty level inherent to the random amount $\xi_{t}$.

\section{Deforming the Discount Function}

The deformation of the discount function consists in modifying some of the parameters which define it, in particular, the interest rate $(i)$ and/or the cash flows maturities $(t)$. The implementation of these correcting parameters to introduce the inherent risk in an investment project implies its treatment as a whole.

In order to use the method of deforming the discount function we adopt the following reasonable hypothesis: the cash flows with higher maturities have higher risk with respect to those whose time horizon is closer. In general, this premise is true since the closer cash flows, usually, may be estimated with a accuracy higher than those with a later maturity, period during which a larger quantity and variety of contingencies may happen.

In this way, this methodology cannot be employed to assess those random investments whose initial cash flows are more difficult to estimate than the later ones; this is because most contingencies are expected at the beginning of the investment. This is, for example, the case of the exploitation of certain types of plantations, whose initial cash flows are very volatile. In effect, at the beginning of the cultivation, the risks are higher because of the seed germination and the initial development of the plant (Van Horne, 2001).

In spite of this limitation, deforming the discount function is a consolidated method. Given its importance in the analysis of financial transactions and in the project assessment, we are going to recall the main procedures to deform the discount function: modifying the interest rate with an additional premium and using a divisor, and modifying the maturities of cash flows.

\subsection{Introducing an Additional Risk Premium to the Discount Rate}

Modifying the discount rate in the expression of a discount function is one of the most used methods to assess certain investments in a context of uncertainty. The procedure presented in this paragraph adds a risk premium, denoted by $p$, to the interest rate, giving rise to a new discount rate:

$$
i^{*}=i+p
$$

This premium has to be positive and its value must be directly related with the risk inherent to the project (Sapag \& Sapag, 2014; Bodie \& Merton, 2000). Under these conditions, the modified net present value is the following:

$$
N P V^{*}=-I_{0}+\sum_{t=1}^{n} E\left(\xi_{t}\right)(1+i+p)^{-t}
$$


As expected, $N P V^{*}$ is smaller than $N P V$ and this is logical since its mathematical expression includes the transaction risk in the discount rate.

\subsection{Introducing a Divisor of the Discount Rate}

This method is a multiplicative version of introducing an additional risk premium to the discount rate, and it consists in applying a correcting denominator, $z$, to the discount rate, $i$, given rise to a new rate discount:

$$
i^{*}=i / z
$$

where $z$ is a value between 0 and 1, inversely related with the transaction risk. Under these conditions, we can calculate the modified net present value of the uncertain future cash flows by using the new discount rate, remaining:

$$
N P V^{*}=-I_{0}+\sum_{t=1}^{n} E\left(\xi_{t}\right)\left(1+i^{*}\right)^{-t}=-I_{0}+\sum_{t=1}^{n} E\left(\xi_{t}\right)(1+i / z)^{-t} .
$$

As expected, $N P V^{*}$ is smaller than $N P V$.

\subsection{Introducing a Multiple of the Cash Flow Maturities}

An alternative way to include the risk in the discount function is to use a factor, $u$, which modifies the maturities of cash flows:

$$
t^{*}=u t
$$

where $u$ is a parameter greater than 1 , directly related with the transaction risk.

As $u$ increases, the expected maturities of the transaction are further. Thus, the discount function value decreases and hence the corrected net present value of the expected future cash flows also decreases:

$$
N P V^{*}=-I_{0}+\sum_{t=1}^{n} E\left(\xi_{t}\right)(1+i)^{-u t}
$$

\subsection{Relationship between the Parameters of the Correcting Methods}

The methodologies presented in subsections 3.1, 3.2 and 3.3 present a common disadvantage: their high degree of subjectivity to quantify the value of the considered element of risk. Its determination is based on the preferences and the own experience of an expert.

The key difference between them is that the introduction of the risk in the discount function considers the project as a whole, whilst the criterion based on the use of correcting coefficients considers different coefficients for every cash flow, according to their own characteristics. However, modifying the discount function is the most suitable method to introduce the risk if the future cash flows are correlated between them (Suárez, 2013).

\begin{tabular}{|c|c|c|c|}
\hline Parameter & $p$ & $z$ & $u$ \\
\hline \multirow{3}{*}{$\alpha_{t}$} & $\alpha=\frac{(1+i)^{t}}{2}$ & $(1+i)^{t}$ & \\
\hline & $\alpha_{t}=\overline{(1+i+p)^{t}}$ & $\alpha_{t}=\overline{(1+i / z)^{t}}$ & $\alpha_{t}=(1+i)^{(1-u) t}$ \\
\hline & $\alpha_{t+1}=\alpha_{t} \frac{1+i}{1+i+X}<\alpha_{t}$ & $\alpha_{t+1}=\alpha_{t} \frac{1+i}{1+i / z}<\alpha_{t}$ & $\alpha_{t+1}=\alpha_{t}(1+i)>\alpha_{t}$ \\
\hline$p$ & & $p=\frac{i}{z}-i$ & $p=(1+i)^{u}-(1+i)$ \\
\hline$z$ & & & $z=\frac{i}{(1+i)^{u}-1}$ \\
\hline
\end{tabular}

In Table 1, we are going to show the mathematical relationship between the modifying parameters of the discount function and the correcting coefficients of the expected cash flows.

Table 1. Relationship between all correcting parameters. 
Observe that most cases in Table 1 imply that the correcting coefficients $\alpha_{t}$ are decreasing which does not seem a reasonable assumption.

\section{Modifying the Time in the Expression of the Discount Function}

\subsection{Introduction}

As indicated, the methodologies implemented in Section 3 lead to unrealistic properties of the respective correcting parameters of cash flows except when using a multiple of the cash flows maturities. The model we are going to present in this Section is based on this last methodology (presented in Section 3.3) and is developed in order to lead to a more accurate result. In effect, in this novel approach the risk is based on the creditor perception about obtaining the future cash flows. More specifically, the risk is measured through the delay in the receipt of the cash flow with respect to the initially agreed maturity. Therefore, the delay in the payment of debts to creditors will be considered the main indicator of the risk inherent to a project.

In this way, our model to introduce the risk is based on the use of the expected maturities $(s)$ of cash flows instead of the initially agreed ones $(t)$ in the project. This new model will imply a smaller value of the discount function used in the assessment of the $N P V$ of the project. Thus, the delay in payment, denoted by $r$, is defined as:

$$
s:=t+r .
$$

Therefore, our aim is to derive the relationship between the debt maturities $(t)$ defined before starting the project, and their corresponding expected delays $(r)$. To do this, we are going to use the information provided by Intrum Justitia included in the "Payment Report 2015". This report presents the average payment maturities that have been contractually agreed and the average time that customers actually take to pay. The information is presented for private (Business-to-Consumer and Business-to-Business) and public companies in Spain. The average maturity data for each of these types of companies are as follows:

1) Business-to-Consumer (B2C) companies:

a. Average contractual payment in days: 43.9 .

b. Average time that customers actually take to pay: 45 .

2) Business-to-Business (B2B) companies:

a. Average contractual payment in days: 56 .

b. Average time that customers actually take to pay: 69.5 .

3) Public companies:

a. Average contractual payment in days: 70.4.

b. Average time that customers actually take to pay: 103 .

\subsection{The model}

Krugman's curve (see Figure 1) relates the maturities of the external debt of a country with the expected dates of its creditors to be reimbursed.

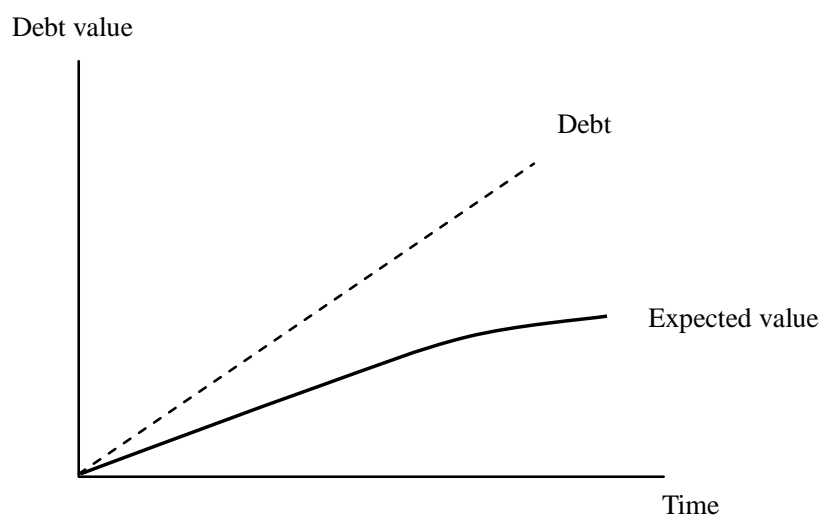

Figure 1. Krugman's curve 
The Krugman's curve explains, in the context of the external debt of a country, how the increase of the external debt of a country also leads to an increment of its expectation of its creditors to be refunded. This increment is declining, as debt maturities increases (Flores et al., 2007).

Below, we conduct an adaptation of the Krugman's curve to explain the relationship between debt maturities of a company and the corresponding expectations to be obtained. To do this, we have to take into account that the future debts are cumulative over time whereby they exhibit an increasing trend as shown in Figure 2:

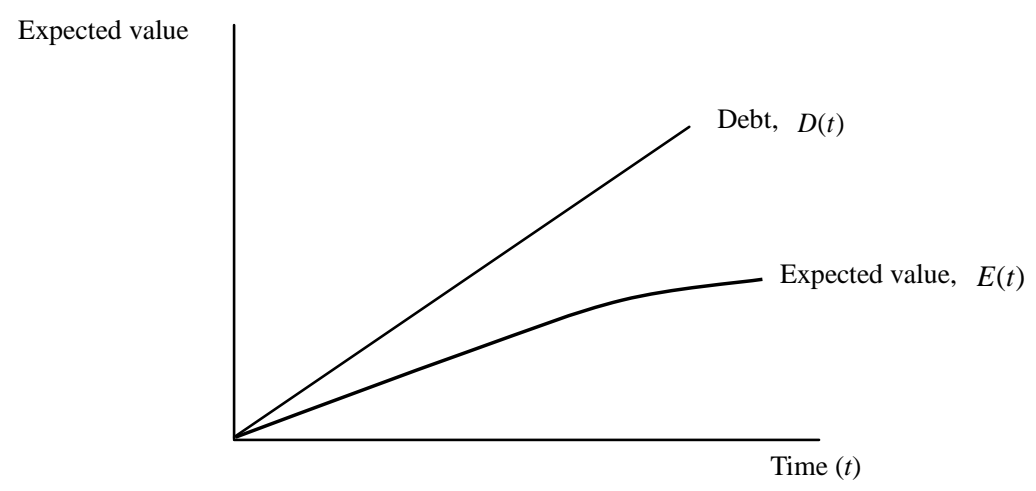

Figure 2. Krugman's curve adaptation

From the graphical representation, it is clear that the expectation of obtaining the debt amounts increases less than such debt values, as time increases.

More specifically, from the creditor point of view, the company owes an amount that increases linearly with time. Whilst the debt expected value (concave function) is also increasing, this rise has a decreasing trend. This is because the events in the distant future are more difficult to prevent, which results in higher risks. Thus, greater maturities imply greater reductions in payment expectations.

On the other hand, we are going to assume that the company debt follows a density function with quantity $\mathrm{d}(x)$, where $0<x<\infty$ :

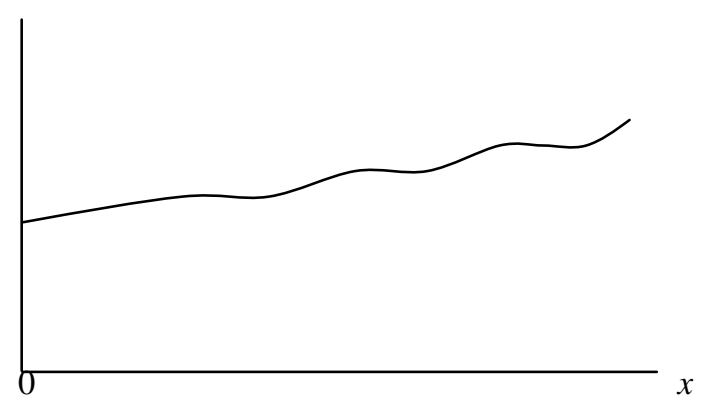

Figure 3. Density function of the debt amount according to time

Therefore, the expression of the interest-free cumulative debt is as follows:

$$
D(t)=\int_{0}^{t} d(x) d x
$$

that, in general, is not a straight line. However, for simplicity, we will consider the linear case, as previously indicated. Its graphical representation is: 


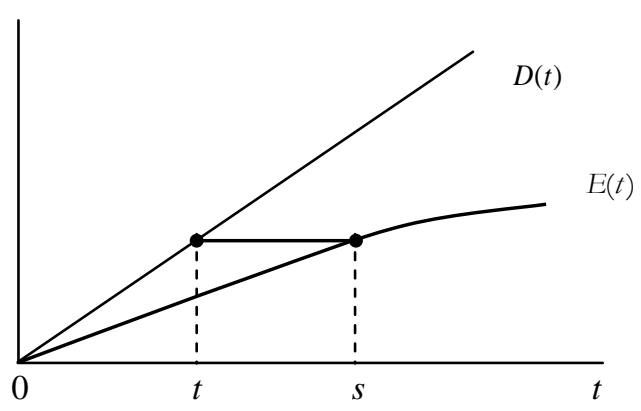

Figure 4. Cumulative debt and payment expectations

The creditor has accumulated at time $t$ an amount of debt to be received, $D(t)$, but this is not expected to be obtained until later, $s$, as seen in Figure 4. So, the following equation holds:

$$
D(t)=E(s) \text {. }
$$

At the beginning of the project (instant 0 ), we assume that $D^{\prime}(0)=E^{\prime}(0)$ which means that the initial instantaneous rate in the debt payment by the debtor is equal to the initial instantaneous rate in the total debt. Our proposal is that, in accordance to Krugman's model, the total debt has a linear evolution whilst the expectation of receipt has a logarithmic behavior (Cruz \& Sánchez, 2013). In effect, suppose that:

$$
D(t)=d t
$$

and

$$
E(t)=\ln (1+\beta t) .
$$

At instant $t=0$ :

$$
D^{\prime}(0)=d .
$$

And

$$
E^{\prime}(0)=\beta \text {. }
$$

According to Equation (15), one has:

$$
d=\beta
$$

and

$$
d t=\ln (1+\beta s) .
$$

Therefore,

$$
s=\frac{e^{\beta t}-1}{\beta} .
$$

By using the expected time, $s$, instead of the initially agreed time of the project, $t$, in the exponential discount function, it remains as follows:

$$
F(t)=\exp (-k s)=\exp \left\{-k \frac{\exp (\beta t)-1}{\beta}\right\} .
$$

Observe that the instantaneous discount rate of this new discount function:

$$
\delta(t)=-\frac{\mathrm{d} \ln F(t)}{\mathrm{d} t}=\frac{k}{\beta} \exp (\beta t)
$$

is, as expected, increasing. Finally, to obtain the value of the constant parameter, $\beta$, in an objective way, we change the initially agreed expirations to the expected maturities. To do this, we use the current information (average contractual payment in days and average time that customers actually take to pay) provided by Intrum Justitia in the "Payment Report 2015", which gives place to the following value of $\beta$ depending on the type of company:

- $\beta=0.00112$ for Business-to-Consumer (B2C) companies. 
- $\beta=0.00745$ for Business-to-Business (B2B) companies.

- $\beta=0.01021$ in the case of public companies.

\section{Conclusions}

In order to determine the net present value of an investment project, it is necessary to use some adjustment criteria able to forecast the expected cash flows maturities according to the degree of risk that the project involves.

First, once recalled the different methods employed to introduce the risk in the assessment of an investment project, the relationship among them have been summarized. Then we have developed a new, more objective methodology to include the risk when determining the NPV of an investment. The presented model relates the risk inherent to a project with its maturity based on the expectation that the creditor has about obtaining the corresponding cash flows. Therefore, in this work, the risk has been identified to the delay of the maturities of the cash flows involved in the project. In this way, this new model uses, in the expression of the discount function, the expected maturities rather than the due initially agreed dates.

Our methodology is based on an adaptation of the Krugman's curve from which we are able to derive a relationship between the maturities involved in a project and their respective delays. This treatment of risk represents a new point of view in the assessment of investment projects where some of their parameters (cash flows or interest rate) are uncertain.

\section{References}

Bodie, Z., \& Merton, R. C. (2000). Finance. New Jersey, United States of America: Prentice Hall.

Brealey, R., \& Myers, S. (2002). Principles of Corporative Finance. New York, United States of America: McGraw-Hill.

Brealey, R., Myers, S., \& Marcus, A. (2014). Fundamentals of Corporate Finance (8th ed.). New York, United States of America: McGraw-Hill.

Cruz Rambaud, S., \& Sánchez Pérez, A. M. (2013). A time-Perception Approach for the Treatment of Risk in Projects Appraisal. International Journal of Intelligent Systems, 28(2), 139-151. Retrieved from http://onlinelibrary.wiley.com/doi/10.1002/int.21561/abstract

Cruz Rambaud, S., \& Valls Martínez, M. C. (2008). Introducción a las Matemáticas Financieras (2nd ed.). Madrid, Spain: Pirámide.

De Pablo López, A. (1991). Préstamos de Duración Variable en Función de las Tasas de Inflación. Cuadernos Aragoneses de Economía, 6, 83-92.

De Pablo López, A. (1998). Some Factors for the Correction of the Inflation Effect in Financial Transactions. First Spanish-Italian Meeting on Financial Mathematics. Servicio de Publicaciones de la Universidad de Almería, 29-40.

De Pablo López, A. (2000). Matemática de las Operaciones Financieras (Tomos I and II). Madrid, Spain: Universidad Nacional de Educación a Distancia (UNED).

Fernández, A., \& García Olalla, M. (1992). Las Decisiones Financieras de la Empresa. Barcelona, Spain: Ariel Economía.

Flores Prieto, P., Fullerton, T. M., \& Olivas Andrade, C. (2007). Evidencia Empírica sobre Deuda Externa, Inversión and Crecimiento en México, 1980-2003. Análisis Económico, 12(50), 149-171. Retrieved from http://www.redalyc.org/articulo.oa?id=41305008

Gil Luezas, M. A., \& Gil Peláez, L. (1987). Matemáticas de las Operaciones Financieras. Madrid, Spain: Universidad Nacional de Educación a Distancia (UNED).

Gil Peláez, L. (1992). Matemática de las Operaciones Financieras. Madrid, Spain: AC.

Jiménez Caballero, J. L., Pérez López, C., \& De la Torre Gallegos, A. (2003). Gestión Financiera de la Empresa. Madrid, Spain: Pirámide.

Loewenstein, G., Read, D., \& Baumeister, R. (2003). Time and Decision: Economic and Psychological Perspectives on Intertemporal Choice. New York, United States of America: Russell Sage Foundation. Retrieved from https://www.russellsage.org/publications/time-and-decision

Loring, J. (2007). La Gestión Financiera. Bilbao, Spain: Deusto. 
Sapag, N., \& Sapag, R. (2014). Preparación y Evaluación de Proyectos (6th ed.). Santiago de Chile, Chile: McGraw-Hill.

Suárez, A. (2013). Decisiones Óptimas de Inversión y Financiación en la Empresa (21th ed.). Madrid, Spain: Pirámide. Retrieved from http://www.edicionespiramide.es/libro.php?id=3565724

Van Horne, J. (2001). Financial Management and Policy (21th ed.). New Jersey, United States of America: Prentice-Hall.

\section{Copyrights}

Copyright for this article is retained by the author(s), with first publication rights granted to the journal.

This is an open-access article distributed under the terms and conditions of the Creative Commons Attribution license (http://creativecommons.org/licenses/by/3.0/). 